•研究报告・

\title{
秦岭国家植物园蝴蝶群落结构与多样性
}

\author{
房丽君 ${ }^{*}$ 张宇军 ${ }^{1}$ 邢小宇 ${ }^{2}$ \\ 1 (陕西省植物资源保护与利用工程技术研究中心, 陕西省西安植物园(陕西省植物研究所), 西安 710061) \\ 2 (秦岭国家植物园, 西安 710061)
}

\begin{abstract}
摘要: 为了查明秦岭国家植物园蝴蝶资源和多样性状况, 本研究选取了 5 种生境, 利用样线法进行了 3 年的蝴蝶多 样性观测。结果表明: 秦岭国家植物园蝴蝶共有 5 科 76 属 134 种; 物种丰富度指数、物种多样性指数、均匀度指数 和优势度指数分别为 $1.3295 、 3.4616 、 0.7068$ 和 0.7656 ; 其中蛱蝶科属数及物种数最多(33属65种), 凤蝶科最低(5属 10 种); 蛱蝶科物种多样性指数及物种丰富度指数最高, 分别为 2.8525 及 1.3622 ; 凤蝶科多样性指数最低(1.4936); 粉蝶科物种丰富度指数最低 $(0.2790)$ 。5种生境中, 随着植被丰富度的增加, 蝴蝶多样性指数上升。
\end{abstract}

关键词: 昆虫纲; 鳞翅目; 蝴蝶多样性; 物种丰富度

\section{Butterfly community structure and diversity in Qinling National Botanical Garden, China}

\author{
Lijun Fang ${ }^{*}$, Yujun Zhang ${ }^{1}$, Xiaoyu Xing ${ }^{2}$ \\ 1 Shaanxi Engineering Research Centre for Conservation and Utilization of Botanical Resources, Xi'an Botanical \\ Garden of Shaanxi Province (Institute of Botany of Shaanxi Province), Xi'an 710061 \\ 2 Qinling National Botanical Garden, Xi'an 710061
}

\begin{abstract}
In order to determine butterfly resources and diversity status of the Qinling National Botanical Garden, we used the transect method across three years to observe butterflies within five habitats. A total of 134 species were recorded, belonging to 5 families and 76 genera. The species richness index, diversity index, evenness index and dominance index were 1.3295, 3.4616, 0.7068 and 0.7656, respectively, among them, Nymphalidae had the largest number of genera (33) and species (65), while Papilionidae had only 5 genera and 10 species. Nymphalidae had the highest diversity index (2.8525) and richness index (1.3622). Papilionidae had the lowest diversity index (1.4936) and Pieridae had the lowest richness index (0.2790). The comparison of butterfly diversity indicators in different habitats showed that butterfly diversity index increased with the increase of vegetation richness. These results show an abundance of butterfly diversity, indicating that Qinling National Botanical Garden may be of significant conservation value.
\end{abstract}

Key words: Insecta; Lepidoptera; butterfly biodiversity; species richness

秦岭国家植物园是目前全世界面积最大、植被 分带最清晰、最具自然风貌的植物园，也是我国第 一个国家级植物园。该园以保护生物多样性为宗旨, 是兼具物种保育、科学研究、公众教育、生态旅游 等功能为一体的综合性植物园。除了保护优良的生 态环境和丰富的植物资源, 植物园还是熊猫 (Ailuropoda melanoleuca)、朱噮(Nipponia nippon)、
川金丝猴(Rhinopithecus roxellana)、羚牛(Budorcas taxicolor)、三尾凤蝶(Bhutanitis thaidina)等数十种国 家珍稀保护动物的栖息地。

蝴蝶以其在自然界中容易观察、捕捉、标记及 鉴定等特性, 成为种群及生态系统水平研究的良好 材料(Nowicki et al, 2008); 同时，它们具有多样的 生态特性和生境要求, 对栖息地植被及微环境变化 
十分敏感, 具有广泛生物地理学和生态学探针的功 能, 可以用来监测环境变化趋势, 从而成为环境监 测的有效指示物种, 研究其多样性既有理论意义, 又有应用价值。

近年来, 国内许多地区开展的蝴蝶研究主要有 蝴蝶群落结构与多样性(如杨大荣, 1998; 胡冰冰等, 2010; 梅杰等, 2015; 翁锦洇等, 2017)及多样性与环 境变化的相关性(如左自途等, 2008; 邓合黎等, 2012; 郝淑莲等, 2019)等。对陕西秦岭地区蝴蝶多 样性进行的研究主要有: 周欣等(2001)记录秦岭南 坡大熊猫保护区蝶类191种; 周尧和邱琼华(1962) 记录太白山蝴蝶98种, 并对种类及其海拔分布和寄 主植物做了描述; 高可等(2013)对太白山南坡的蝴 蝶多样性及区系特征进行了研究, 记录蝶类126种; 苑彩霞等(2012)对陕西秦岭平河梁自然保护区的蝶 类进行了资源调查和区系分析，记录蝶类68种; 郭 类进行调查, 分析了该地区蝶类资源的垂直分布, 发现蝴蝶种类及其活动规律随着植被带谱的变化 而变化, 植物种类是决定蝴蝶种类组成和分布的主 要因素。

秦岭国家植物园是秦岭北坡最具代表性的区 域之一, 蝴蝶资源丰富, 但目前尚未见到对秦岭国 家植物园蝴蝶多样性的研究报道。为此, 我们在承 担生态环境部蝴蝶多样性观测课题时, 选取了该植 物园作为观测调查的样区，于2016-2018年进行了 蝴蝶多样性观测, 并对其群落结构及多样性进行分 析探讨, 以期揭示秦岭国家植物园蝴蝶物种资源和 多样性现状及不同生境的蝴蝶多样性特征, 为秦岭 地区蝴蝶资源保护、利用以及环境质量的监测和评 价提供基础资料。

\section{1 研究方法}

\section{1 研究地概况}

秦岭国家植物园规划总面积 $639 \mathrm{~km}^{2}$, 位于 $108^{\circ} 13^{\prime}-108^{\circ} 29^{\prime}$ E、 $33^{\circ} 43^{\prime}-34^{\circ} 04^{\prime} \mathrm{N}$, 由北向南依次 为平原、丘陵、低山、中山和高山五种地貌单元, 形 成了一个完整的立体生态系统。该园地处亚热带和 暖温带分界线，属暖温带大陆性山地气候。园内共 有13条河流, 年平均降水量800-900 mm, 年平均温 度8 $-10^{\circ} \mathrm{C}$ 。海拔跨度 $480-3,000 \mathrm{~m}$, 由低到高依次为 杂果林、次生灌丛及阔叶林带、针阔混交林带(侧柏

(Platycladus orientalis)林带和锐齿栎(Quercus aliena var. acuteserrata)林带, 2,000-2,400 m)、红桦(Betula albosinensis)林带(2,400-2,600 m)、巴杉冷杉(Abies fargesii) 林带 (2,600-2,800 m)、太白红杉 (Larix chinensis)林带(2,900 m左右)、灌丛及草甸(2,900 m 以上)。主要景区分 $A 、 B 、 C 及 D$ 四个区域, 其中C 区为生物就地保护区和植被恢复区, 规划面积 $575.31 \mathrm{~km}^{2}$, 以保护现有生物的栖息地和生存环境 为目标，进行科学观测和监测，按照保护分区有针 对性地开展研究和保护, 同时对受到破坏的浅山地 区进行植被恢复重建。

\section{2 调查地点及样线设置}

按照全国蝴蝶多样性观测要求，在秦岭国家植 物园根据不同的植被类型、生境和人类活动影响等 因素，参考不同蝴蝶的栖息特点、生态习性、寄主 分布范围等, 选取纯天然林、天然林(沿园区旅游主 干道)、半人工林、河岸带及农耕地等5种生境, 每 个生境内设置1条样线(图1)。各生境植被及海拔状 况如下:

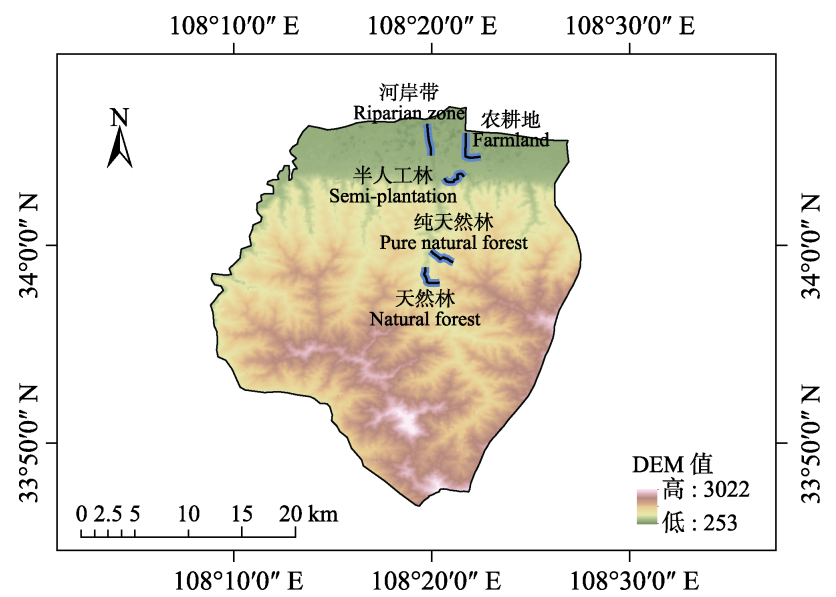

图1 秦岭国家植物园蝴蝶调查样线分布图

Fig. 1 Map of survey transects of butterfly in Qinling National Botanical Garden

(1)纯天然林生境。位于秦岭国家植物园的纯天 然林内，林内道路为羊肠小道，植被覆盖率为 $93 \%$, 海拔650-860 m, 植被类型为阔叶林带。主要植物为 栓皮栋 (Quercus variabilis) 、油松 (Pinus tabuliformis)、侧柏、杜仲(Eucommia ulmoides)、胡 桃(Juglans regia)、山杨(Populus davidiana)、青鈇杨 (Rhus potaninii)、陕西鹅耳枥(Carpinus shensiensis)、 陕西小檗(Berberis shensiana)、刚竹(Phyllostachys 
bambusoides)、陕西荚蒾(Viburnum schensianum)、 连戴(Forsythia suspensa)、互叶醉鱼草(Buddleja alternifolia)、多花胡枝子(Lespedeza floribunda)、小 白酒草(Conyza canadensis)等。

(2)天然林生境。位于秦岭国家植物园的天然林 内, 但有园区的主干道(水泥路)贯穿其间, 并有游 客活动, 植被覆盖率为90\%, 海拔700-730 m, 植被 类型为阔叶林带。主要植物有青檀 (Pteroceltis tatarinowii)、栓皮栋、陕西鹅耳杯、垂柳(Salix babylonica)、胡桃、山杨、国槐(Sophora japonica)、 红叶李 (Prunus cerasifera)、尖叶女贞(Ligustrum lucidum)、奕树(Koelreuteria paniculata)、苦皮藤 (Celastrus angulatus)、互叶醉鱼草、小白酒草、地 榆(Sanguisorba officinalis)等。

(3)半人工林生境。位于秦岭国家植物园的园林 展览区, 海拔580-670 m, 植被类型为阔叶林带。主 要植物有油松、侧柏、玉兰(Magnolia denudata)、 红叶李、垂柳、杏(Armeniaca vulgaris)、银杏(Ginkgo biloba)、国槐、紫薇(Lagerstroemia indica)、刚竹、 大叶黄杨(Buxus megistophylla)、小白酒草、狗尾草 (Setaria viridis)、毛苕子(Iicia villosa)等。

(4)河岸带生境。位于田峪河的村落附近的河岸 带, 海拔 $440 \mathrm{~m}$, 植被类型为次生草灌丛。主要植物 有构树(Broussonetia papyifera)、多花胡枝子、迎春 花 (Jasminum nudiflorum) 、野胡萝卜 (Daucus carota)、艾草(Artemisia argyi)、毛苦子、苜宿 (Medicago sativa)、小白酒草、灰绿藜(Chenopodium glaucum)、酢浆草(Oxalis corniculata)、茜草(Rubia cordifolia)、播娘蒿(Descurainia sophia)等。

(5)农耕地。位于紧邻植物园的平原农耕带, 海 拔 $460 \mathrm{~m}$, 植被类型为农作物及人工果园, 种植的 作物主要有玉米(Zea mays)、李子(Prunus salicina)、 桃(Prunus persica)、狝猴桃(Actinidia chinensis)、小 麦(Triticum aestivum)、油菜(Brassica napus)等。

\section{3 调查方法}

根据生态环境部蝴蝶多样性观测网络的统一 要求(马方舟等, 2018), 于2016-2018年每年的5-8月 采用样线法进行观测调查, 每月 1 次, 每次在蝴蝶 活动频繁的9:00-17:00进行观测记录。每条样线长 $2 \mathrm{~km}$, 划分成 10 个样段, 每个样段长 $200 \mathrm{~m}$, 各样 线、样段设置明显标识物并编号标记, 每个样段内 的生境类型或土地利用方式相同(马方舟等, 2018)。
利用GPS记录样线位置。观测时沿样线缓慢匀速前 行, 速度1-1.5 km/h。记录样线左右 $2.5 \mathrm{~m}$ 、上方 $5 \mathrm{~m}$ 、 前方 $5 \mathrm{~m}$ 范围内见到的所有蝴蝶的种类和数量, 不 重复计数同一只个体和身后的蝴蝶(马方舟等, 2018)。在悬崖或水边, 可沿样线仅记录一侧宽度为 5 m范围内的数据(HJ 710.9-2014)。

对于不能确定的种类，网捕后进行鉴定，种类 确定后原地释放; 当时不能确定的种类, 每种网捕 1-2只, 用三角纸袋包好并编号, 带回实验室鉴定、 统计记录。

\section{4 分类依据}

采用Jong等(1996)、Wahlberg等(2003)的五科分 类系统, 眼蝶、环蝶及喙蝶归入蛱蝶科, 绢蝶归入 凤蝶科。依据《中国蝶类志》(周尧, 1994)、《中国 蝴蝶分类与鉴定》(周尧, 1998) 和《中国蝴蝶图鉴》 (武春生和徐堉峰, 2017)等资料进行分类鉴定。

\section{5 数据分析}

采用 Menhinick 物种丰富度指数 $\left(d_{s}\right)$ 、 Shannon-Wiener多样性指数 $\left(H^{\prime}\right)$ 、Pielou均匀度指数 $\left(J^{\prime}\right)$ 、Berger-Parker优势度指数 $(d)$ 和Jaccard群落相似 性系数 $\left(C_{\mathrm{j}}\right)$ 分析蝶类群落 $\alpha$ 及 $\beta$ 多样性(马克平, 1994 ; 马克平和刘玉明, 1994; 马克平等, 1995; 吴坤君等, 2005; Magurran, 2011)。

$$
\begin{aligned}
& d_{s}=G / N_{s}^{1 / 2} \\
& H^{\prime}=-\Sigma P_{\mathrm{i}} \ln P_{\mathrm{i}} \\
& J^{\prime}=H^{\prime} / \ln S \\
& d=N_{\max } / N_{t}
\end{aligned}
$$

式中, $G$ 为各科的物种数, $N_{s}$ 为各科所包含的个体数 之和。 $P_{\mathrm{i}}=N_{\mathrm{i}} / N, N_{\mathrm{i}}$ 为物种 $\mathrm{i}$ 的个体数, $N$ 为样本总个 体数。S为物种数。 $N_{\max }$ 为优势种的个体数量之和, $N_{t}$ 为全部种类的个体数量之和。

$$
C_{\mathrm{j}}=j /(a+b-j)
$$

其中, $j$ 为两个生境共有种数; $a$ 和 $b$ 分别为生境 $\mathrm{A}$ 和 $\mathrm{B}$ 的物种数。 $C_{\mathrm{j}}$ 为 $0.00-0.25$ 时, 为极不相似; $C_{\mathrm{j}}$ 为 $0.25-0.50$ 时, 为中等不相似; $C_{\mathrm{j}}$ 为 $0.50-0.75$ 时, 为中 等相似; $C_{\mathrm{j}}$ 为 $0.75-1.00$ 时, 为极相似。

计算属种比值, 即属数/种数。

当某种蝴蝶的个体数 $\geq 150$ 只时定为优势种; 仅记录到 1 只个体的定为稀有种, 记录个体数为 $2-5$ 只的定为少见种(胡冰冰等, 2010)。 


\section{结果}

\section{1 秦岭国家植物园蝴蝶群落组成}

2016-2018年共记录到蝴蝶 10,158只, 隶属5科 76属134种(附录1)。

由表1可知, 各科中属数由高到低排序为: 蛱 蝶科 > 灰蝶科 > 弄蝶科 > 粉蝶科 > 凤蝶科; 各科中物种数由高到低排序为: 蛱蝶科 $>$ 灰蝶 科 $>$ 弄蝶科 $=$ 粉蝶科 $>$ 凤蝶科; 属及种的数量 以蛱蝶科最丰富, 达33属65种, 分别占蝴蝶总属数 及种数的 $43.42 \%$ 和 $48.51 \%$; 凤蝶科的属及种数最 少, 仅 5 属 10 种, 分别占总属数和种数的 $6.58 \%$ 和 $7.46 \%$ 。个体数量排序为粉蝶科 $>$ 灰蝶科 $>$ 蛱蝶 科 > 凤蝶科 $>$ 弄蝶科, 以粉蝶科最多, 达3,714只, 占总个体数的 $36.58 \%$, 弄蝶科的个体数最少, 为 299 只，占总个体数的 $2.95 \%$ 。

据属种比值系数分析, 秦岭国家植物园蝶类为 0.57 , 小于该比值的科有蛱蝶科、风蝶科和粉蝶科,
其中蛱蝶科属种比值为 0.51 , 与整个蝶类的属种比 值(0.57)最为接近; 灰蝶科及弄蝶科属种比值大于 0.57 , 分别为 0.72 及 0.71 , 说明这两科在该地区分布 的属级单元较为丰富。

\section{2 秦岭国家植物园蝴蝶优势种及稀有种}

由表 2 可知, 该地区个体数量在 150 只以上的优 势种有 17 种，占总种数的 $12.69 \%$, 但它们的个体数 量 $(7,777$ 只)却占到总个体数的 $76.56 \%$, 其中粉蝶科 的优势种数量最多，占到总个体数的 $33.59 \%$ 。这些 种构成了秦岭国家植物园蝴蝶的优势类群。

调查发现，该地区的稀有种有姝美风蝶 (Papilio macilentus)、残锷线蛱蝶(Limenitis sulpitia)、 虬眉带蛱蝶(Athyma opalina)、蛛环蛱蝶(Neptis arachne)、棕褐黛眼蝶(Lethe christophi)、陕灰蝶 (Shaanxiana takashimai)、华灰蝶(Wagimo sulgeri)、 绿弄蝶(Choaspes benjaminii)等23种，占总蝴蝶物种 数的 $17.16 \%$; 少见种有迷蛱蝶(Mimathyma chev$a n a) 、$ 戟眉线蛱蝶(Limenitis homeyeri)、羚环蛱蝶

表1 秦岭国家植物园蝴蝶种、属、个体数及其比值和所占百分比

Table 1 Number of the species, genera, individuals, ratio of genus / species and percentage of butterfly on the level of families in Qinling National Botanical Garden

\begin{tabular}{lllll}
\hline $\begin{array}{l}\text { 科 } \\
\text { Family }\end{array}$ & $\begin{array}{l}\text { 属数 } \\
\text { Genera number (\%) }\end{array}$ & $\begin{array}{l}\text { 种数 } \\
\text { Species number (\%) }\end{array}$ & $\begin{array}{l}\text { 属种比值系数 } \\
\text { Ratio of genus / species }\end{array}$ & $\begin{array}{l}\text { 个体数 } \\
\text { Individuals number (\%) }\end{array}$ \\
\hline 凤蝶科 Papilionidae & $5(6.58)$ & $10(7.46)$ & 0.50 & $473(4.66)$ \\
粉蝶科 Pieridae & $8(10.53)$ & $17(12.69)$ & 0.47 & $3,714(36.58)$ \\
蛱蝶科 Nymphalidae & $33(43.42)$ & $65(48.51)$ & 0.51 & $2,277(22.42)$ \\
灰蝶科 Lycaenidae & $18(23.68)$ & $25(18.66)$ & 0.72 & $3,395(33.42)$ \\
开蝶科 Hesperiidae & $12(15.79)$ & $17(12.69)$ & 0.71 & $299(2.95)$ \\
合计 Total & $76(100)$ & $134(100)$ & 0.57 & $10,158(100)$ \\
\hline
\end{tabular}

表2 秦岭国家植物园蝴蝶优势种(个体数 $\geq 150$ 只)

Table 2 The dominant species (individual $\geq 150$ ) of butterflies in Qinling National Botanical Garden

\begin{tabular}{|c|c|c|c|}
\hline $\begin{array}{l}\text { 优势种 } \\
\text { Dominant species }\end{array}$ & $\begin{array}{l}\text { 个体数 } \\
\text { Individual numbers (\%) }\end{array}$ & \begin{tabular}{|l}
$\mid$ 优势种 \\
Dominant species
\end{tabular} & $\begin{array}{l}\text { 个体数 } \\
\text { Individual numbers (\%) }\end{array}$ \\
\hline 凤蝶科 Papilionidae & $307(3.02)$ & 蛱蝶科 Nymphalidae & 1,203 (11.84) \\
\hline 碧凤蝶 Princeps bianor & $154(1.52)$ & 扬眉线蛱蝶 Limenitis helmanni & $609(6.00)$ \\
\hline 冰清绢蝶 Parnussiur glacialis & $153(1.51)$ & 小环蛱蝶 Neptis sappho & $250(2.46)$ \\
\hline 粉蝶科 Pieridae & 3,412 (33.59) & 黄钩蛱蝶 Polygonia c-aureum & 344 (3.39) \\
\hline 斑缘豆粉蝶 Colias erate & $633(6.23)$ & 灰蝶科 Lycaenidae & $2,855(28.11)$ \\
\hline 橙黄豆粉蝶 C. fieldii & $170(1.67)$ & 大紫璃灰蝶 Celastrina oreas & $780(7.68)$ \\
\hline 菜粉蝶 Pieris rapae & $1,670(16.44)$ & 蓝灰蝶 Everes argiades & $680(6.69)$ \\
\hline 东方菜粉蝶 P. canidia & $386(3.80)$ & 锯灰蝶 Orthomiella pontis & $603(5.94)$ \\
\hline 绢粉蝶 Aporia crataegi & $202(1.99)$ & 酢浆灰蝶 Pseudozizeeria maha & $262(2.58)$ \\
\hline 普通绢粉蝶 A. genestieri & $178(1.75)$ & 红珠灰蝶 Lycaeides argyrognomon & $530(5.22)$ \\
\hline 大翅绢粉蝶 A. largeteaui & $173(1.70)$ & & \\
\hline
\end{tabular}


(Neptis antilope)、白钩蛱蝶(Polygonia c-album)、黛 眼蝶(Lethe dura)、蚜灰蝶(Taraka hamada)、钩形黄 斑弄蝶(Ampittia virgata) 等24种, 占总蝴蝶物种数 的 $17.91 \%$ 。建议将上述 47 种蝴蝶列为重点关注对象, 给予特别的关注与有效的保护。

\section{3 蝶类群落的多样性特征}

从表3可看出, 秦岭国家植物园蝶类群落的物 种丰富度指数为 1.3295 , 物种多样性指数达 3.4616 , 均匀度指数为 0.7068 , 优势度指数为 0.7656 , 表明 该地区生态条件良好, 蝶类物种丰富, 群落结构较 为稳定。

各科间物种丰富度指数由高到低依次为: 蛱蝶 科 > 弄蝶科 > 凤蝶科 > 灰蝶科 > 粉蝶科; 蛱 蝶科的物种数最多, 而个体数居中, 故其物种丰富 度指数最高; 粉蝶科物种丰富度指数最低, 因其物 种数较凤蝶科多, 而个体数量是凤蝶科的 7.85 倍。

Shannon-Wiener 多样性指数为蛱蝶科 > 弄蝶 科 $>$ 灰蝶科 $>$ 粉蝶科 $>$ 凤蝶科。Pielou 均匀度 指数为弄蝶科 $>$ 蛱蝶科 $>$ 粉蝶科 $>$ 凤蝶科 $>$ 灰蝶科。Berger-Parker 优势度指数为粉蝶科 $>$ 灰 蝶科 > 凤蝶科 > 蛱蝶科 > 弄蝶科。

蛱蝶科物种丰富度指数(1.3622)和多样性指数 (2.8525) 最高, 均匀度指数 (0.6833) 仅低于弄蝶科, 优势度指数 (0.5283) 次低, 说明蛱蝶科在该地区物 种丰富, 群落结构较为稳定。弄蝶科的多样性指数 (2.1919) 较高, 仅次于蛱蝶科, 均匀度指数 (0.7737) 最高, 优势度指数为 0 , 表明弄蝶科的物种丰富, 种 类间的个体数量差异不明显, 无特别显著的优势种, 整个弄蝶科群落结构稳定, 物种相对平衡。灰蝶科 的多样性指数(2.0823)居中, 优势度指数 (0.8409)次 高, 而均匀度指数(0.6469)最低, 说明在秦岭国家植 物园灰蝶科种类相对较多, 优势种相对集中, 种群
结构处于较不稳定状态。粉蝶科的优势度指数 (0.9187)最高, 多样性指数(1.8496)次低, 均匀度指 数(0.6528)处于相对低位, 说明粉蝶科的物种较为 贫乏, 优势种突出, 其生存与繁育处于较不稳定的 状态。凤蝶科的多样性指数 (1.4936)最低, 均匀度指 数(0.6487)次低, 优势度指数(0.6491)中等, 说明该 科的物种较为贫乏, 物种分布不太均匀, 有部分突 出的优势种, 种群处于中度稳定的状态。

\section{4 不同生境蝶类物种组成、多样性及相似性比较}

\subsection{1 不同生境蝴蝶物种组成}

从表 4 可以看出, 不同生境蝴蝶群落的物种数 和个体数存在差异, 其中以纯天然林的物种数和个 体数最多, 为 110 种 3,460 只; 农耕地的物种数和个 体数最少, 为 13 种 1,341 只。种类数各生境由高到低 依次为: 纯天然林 $>$ 天然林 $>$ 半人工林 $>$ 河 岸带 > 农耕地; 个体数各生境由高到低依次为: 纯天然林 > 河岸带 > 天然林 > 半人工林 $>$ 农耕地。

\subsection{2 不同生境蝴蝶群落多样性指数}

由表4可以看出, 不同生境蝴蝶群落各多样性 指数间存在差异。纯天然林、天然林及半人工林 3 种生境的多样性明显好于河岸带和农耕地; 河岸带 和农耕地的优势度指数远高于纯天然林、天然林及 半人工林, 表明多样性指数越好的生境, 其群落结 构越稳定, 各种蝴蝶种群较为平衡, 而生境较差的 环境蝴蝶种类少, 优势种类发生数量较多, 蝴蝶群 落结构处于较不稳定状态。

\subsection{3 不同生境蝴蝶相似性比较}

不同生境蝴蝶群落的相似性系数见表5。由表 中可以看出各生境蝴蝶群落间的相似性系数在 $0.00-0.75$ 之间, 其中相似性系数在 $0.00-0.25$ 之间的 生境有纯天然林和河岸带、纯天然林和农耕地、

表3 秦岭国家植物园蝴蝶多样性指数

Table 3 The diversity indices of butterfly communities in Qinling National Botanical Garden

\begin{tabular}{lllll}
\hline 科 & $\begin{array}{l}\text { 物种丰富度指数 } \\
\text { Family }\end{array}$ & $\begin{array}{l}\text { 多样性指数 } \\
\text { Diversity index }\end{array}$ & $\begin{array}{l}\text { 均匀度指数 } \\
\text { Evenness index }\end{array}$ & $\begin{array}{l}\text { 优势度指数 } \\
\text { Dominance index }\end{array}$ \\
\hline 凤蝶科 Papilionidae & 0.4598 & 1.4936 & 0.6487 & 0.6491 \\
粉蝶科 Pieridae & 0.2790 & 1.8496 & 0.6528 & 0.9187 \\
蛱蝶科 Nymphalidae & 1.3622 & 2.8525 & 0.6833 & 0.5283 \\
灰蝶科 Lycaenidae & 0.4291 & 2.0823 & 0.6469 & 0.8409 \\
弄蝶科 Hesperiidae & 0.9831 & 2.1919 & 0.7737 & 0 \\
合计 Total & 1.3295 & 3.4616 & 0.7068 & 0.7656 \\
\hline
\end{tabular}


表4 秦岭国家植物园不同生境蝴蝶物种组成和多样性指数

Table 4 Species composition and diversity indices of butterflies in different habitats in Qinling National Botanical Garden

\begin{tabular}{|c|c|c|c|c|c|c|}
\hline $\begin{array}{l}\text { 生境 } \\
\text { Habitat }\end{array}$ & $\begin{array}{l}\text { 种数 } \\
\text { Number of species }\end{array}$ & $\begin{array}{l}\text { 个体数 } \\
\text { Number of individuals }\end{array}$ & $\begin{array}{l}\text { 物种丰富度指数 } \\
\text { Species richness index }\end{array}$ & $\begin{array}{l}\text { 多样性指数 } \\
\text { Diversity index }\end{array}$ & $\begin{array}{l}\text { 均匀度指数 } \\
\text { xEvenness index }\end{array}$ & $\begin{array}{l}\text { 优势度指数 } \\
\text { Dominance index }\end{array}$ \\
\hline 纯天然林 Pure natural forest & 110 & 3,460 & 1.8701 & 3.5627 & 0.7579 & 0.3812 \\
\hline 天然林 Natural forest & 98 & 1,801 & 2.3328 & 3.3842 & 0.7365 & 0.3298 \\
\hline 半人工林 Semi-plantation & 69 & 1,361 & 1.8703 & 3.1187 & 0.7366 & 0.2785 \\
\hline 河岸带 Riparian zone & 21 & 2,195 & 0.4482 & 2.1137 & 0.6943 & 0.8105 \\
\hline 农耕地 Farmland & 13 & 1,341 & 0.3550 & 0.8596 & 0.3351 & 0.7867 \\
\hline
\end{tabular}

表5 秦岭国家植物园不同生境中共有蝴蝶种数(对角线上)及相似性系数(对角线下)

Table 5 Number of the shared species (above diagonal) and similarity coefficient (below diagonal) between different habitats in Qinling National Botanical Garden

\begin{tabular}{llllll}
\hline $\begin{array}{l}\text { 生境 } \\
\text { Habitat }\end{array}$ & $\begin{array}{l}\text { 纯天然林 } \\
\text { Pure natural forest }\end{array}$ & $\begin{array}{l}\text { 天然林 } \\
\text { Natural forest }\end{array}$ & $\begin{array}{l}\text { 半人工林 } \\
\text { Semi-plantation }\end{array}$ & $\begin{array}{l}\text { 河岸带 } \\
\text { Riparian zone }\end{array}$ & $\begin{array}{l}\text { 农耕地 } \\
\text { Farmland }\end{array}$ \\
\hline $\begin{array}{l}\text { 纯天然林 Pure natural forest } \\
\text { 天然林 Natural forest }\end{array}$ & 0.67 & 84 & 59 & 17 & 13 \\
半人工林 Semi-plantation & 0.49 & & 58 & 15 & 11 \\
河岸带 Riparian zone & 0.15 & 0.53 & & 16 & 11 \\
农耕地 Farmland & 0.12 & 0.14 & 0.22 & 0.55 & 12 \\
\hline
\end{tabular}

天然林和河岸带、天然林和农耕地、半人工林和河 岸带及半人工林和农耕地, 表明纯天然林、天然林 和半人工林与河岸带和农耕地之间的蝴蝶相似性 为极不相似; 纯天然林和半人工林间蝴蝶的相似性 系数在0.25-0.50之间, 为中等不相似; 纯天然林和 天然林、天然林和半人工林及河岸带和农耕地之间 蝴蝶的相似性系数在 $0.50-0.75$ 之间, 为中等相似, 其中纯天然林和有人类干扰的天然林之间蝴蝶的 相似性系数最高, 为 0.67 , 说明天然林中, 虽有人 类干扰但蝴蝶种类依然近似, 从中也可以看出蝴蝶 发生的种类受植被类型的影响更大。

\section{3 讨论}

植被类型、寄主植物丰富度、蜜源植物及人为 干扰等因素对蝴蝶的群落结构和动态变化具有较 大影响(Corbet, 2000; Inoue, 2003; Dennis et al, 2004; Andrea et al, 2005; Kotiaho et al, 2005), 秦岭国家植 物园的蝴蝶种类丰富、群落结构稳定, 与该地丰富 的植物资源以及近年来实施退耕还林、天然林及水 源涵养区保护等措施密切相关。

纯天然林生境内道路为羊肠小道, 几无游人干 扰, 植被覆盖率达到 $93 \%$, 其蝶类群落多样性指数 和均匀度指数最高, 物种丰富度指数和优势度指数 居中, 表明该生境植被良好, 蝶类种类丰富, 群落
结构较为稳定。天然林生境内有园区的主干道(水泥 路)贯穿其间，有一定的人为干扰，植被覆盖率为 $90 \%$, 该生境蝶类的物种丰富度指数最高, 物种多 样性指数和均匀度指数次高, 优势度指数次低。主 干道的建设可能产生两方面的影响: 一方面降低了 郁闭度, 更有利于蝴蝶的活动和繁殖, 从而使物种 丰富度上升; 另一方面道路的建设破坏了生境, 加 之游人的活动干扰，降低了物种多样性，增加了优 势种类。半人工林生境在秦岭国家植物园的园林展 览区, 为天然林和人工林的混合植被带, 游人可在 其间活动, 其物种丰富度指数、多样性指数及均匀 度指数居中, 而优势度指数最低, 由于展区内部分 种植了人工林, 加之游人的干扰, 多样性指数稍有 下降，但其他指数均处于较好水平，说明该生境较 好, 仍然适宜于蝴蝶的生存和繁殖。河岸带植被类 型为次生草灌从，其物种丰富度指数、多样性指数 及均匀度指数处于次低, 优势度指数最高, 这可能 与其植被条件较为单一密切相关。农耕地植被类型 为人工果园(猕猴桃、李子及桃)及农作物(小麦和油 菜), 其物种丰富度指数、多样性指数及均匀度指数 为最低, 而优势度指数为次高, 这与其植物组成单 一、且大面积栽植、大量喷酒农药和施用化肥密切 相关。由以上不同生境的蝶类多样性指标比较可以 看出, 随着植被丰富度的增加, 蝴蝶物种丰富度、 
多样性指数和均匀度指数随之上升。

梅杰等(2015)的研究表明, 蝶类群落的相似度 与生境质量及植被类型的差异有关。本文的各生境 蝴蝶相似性分析结果表明: 纯天然林与天然林生境 蝴蝶相似度最高, 为中等相似。这两种生境属天然 林, 植被均以阔叶林为主, 植物种类组成较复杂, 类型多样，且人为干扰较少; 而天然林与农耕地生 境蝴蝶的相似度最低, 这可能与其植被结构及人类 干扰程度差异较大密切相关。

致谢: 参与调查的还有吕璇及侯力等多位人员, 在 此一并致谢!

\section{参考文献}

Andrea G, Barbara K, Cleary DFR, Vassiliki K (2005) Butterfly, spider, and plant communities in different land-use types in Sardinia, Italy. Biodiversity and Conservation, 14, 1281-1300.

Chou I, Chiu CH (1962) Butterflies from Mount Taipai and their vertical distribution. Acta Entomologica Sinica, 11(Suppl.), 90-102. (in Chinese with English abstract) [周 尧, 邱琼华 (1962) 太白山的蝶类及其垂直分布. 昆虫学 报, 11(增刊), 90-102.]

Chou I (1994) Monographia Rhopalocerorum Sinensium. Henan Science and Technology Publishing House, Zhengzhou. (in Chinese) [周尧 (1994) 中国蝶类志. 河南 科学技术出版社, 郑州.]

Chou I (1998) Classification and Identification of Chinese Butterflies. Henan Science and Technology Publishing House, Zhengzhou. (in Chinese) [周尧 (1998) 中国蝴蝶分 类与鉴定. 河南科学技术出版社, 郑州.]

Corbet SA (2000) Butterfly nectaring flowers: Butterfly morphology and flower form. Entomologia Experimentalis et Applicata, 96, 289-298.

Deng HL, Ma Q, Li AM (2012) The establishment of the indication on environmental health of butterfly and of the environmental monitoring evaluation system in Chongqing. Acta Ecologica Sinica, 32, 5208-5218. (in Chinese with English abstract) [邓合黎, 马琦, 李爱民 (2012) 重庆市 蝴蝶多样性环境健康指示作用和环境监测评价体系构建. 生态学报, 32, 5208-5218.]

Dennis RLH, Hodgson JG, Grenyer R, Shreeve TG, Roy DB (2004) Host plants and butterfly biology. Do host-plant strategies drive butterfly status? Ecological Entomology, 29, 12-26.

Gao K, Fang LJ, Shang SQ, Zhang YL (2013) Butterfly diversity and faunal characteristics on the south slope of Taibai Mountain, Shaanxi Province of Northwest China. Chinese Journal of Applied Ecology, 24, 1559-1564. (in
Chinese with English abstract) [高可, 房丽君, 尚素琴, 张 雅林 (2013) 陕西太白山南坡蝶类的多样性及区系特征. 应用生态学报, 24, 1559-1564.]

Guo R, Li JP (2010) Vertical distribution of butterfly in Foping National Nature Reserve. Shaanxi Forest Science and Technology, (3), 28-30. (in Chinese with English abstract) [郭荣, 李静平 (2010) 陕西佛坪国家级自然保护区蝶类 垂直分布调查. 陕西林业科技, (3), 28-30.]

Hao SL, Xue QQ, Feng DD, Li XF, Liu Y, Zhang ZW, Men LN (2019) Comparative study on butterfly diversity and niche difference in mountainous region of southern Shanxi Province. Journal of Ecology and Rural Environment, 35, 1314-1321. (in Chinese with English abstract) [郝淑莲, 薛 琪琪, 冯丹丹, 李晓菲, 刘杨, 张志伟, 门丽娜 (2019) 山西南部山地蝴蝶多样性与生态位差异比较研究. 生态 与农村环境学报, 35, 1314-1321.]

Hu BB, Li HH, Liang ZP, Zhao TJ, Ren XB (2010) Diversity and fauna of butterflies in Baxian Mountain State Nature Reserves. Acta Ecologica Sinica, 30, 3226-3238. (in Chinese with English abstract) [胡冰冰, 李后魂, 梁之聘, 赵铁建, 任秀柏 (2010) 八仙山自然保护区蝴蝶群落多 样性及区系组成. 生态学报, 30, 3226-3238.]

Inoue $\mathrm{T}$ (2003) Chronosequential change in a butterfly community after clear-cutting of deciduous forests in a cool temperate region of central Japan. Entomological Science, 6, 151-163.

Jong R, Vane-Wright RI, Ackery PR (1996) The higher classification of butterflies (Lepidoptera): Problems and prospects. Entomologica Scandinavica, 27, 65-101.

Kotiaho JS, Kaitala V, Komonen A, Päivinen JP, Ehrlich PR (2005) Predicting the risk of extinction from shared ecological characteristics. Proceedings of the National Academy of Sciences, USA, 102, 1963-1967.

Ma FZ, Xu HG, Chen MM, Tong WJ, Wang CB, Cai L (2018) Progress in construction of China Butterfly Diversity Observation Network (China BON-Butterflies). Journal of Ecology and Rural Environment, 34, 27-36. (in Chinese with English abstract) [马方舟, 徐海根, 陈萌萌, 童文君, 王晨涁，蔡蕾 (2018) 全国蝴蝶多样性观测网络(China BON-Butterflies) 建设进展. 生态与农村环境学报, 34, 27-36.]

Ma KP (1994) Measurement of biotic community diversity. I. $\alpha$ diversity (Part 1). Chinese Biodiversity, 2, 162-168. (in Chinese) [马克平 (1994) 生物群落多样性的测度方法. I. $\alpha$ 多样性的测度方法(上). 生物多样性, 2, 162-168.]

Ma KP, Liu YM (1994) Measurement of biotic community diversity. I. $\alpha$ diversity (Part 2). Chinese Biodiversity, 2, 231-239. (in Chinese) [马克平, 刘玉明 (1994) 生物群落 多样性的测度方法. I. $\alpha$ 多样性的测度方法(下). 生物多样 性, 2, 231-239.]

Ma KP, Liu CR, Liu YM (1995) Measurement of biotic community diversity. II. $\beta$ diversity. Chinese Biodiversity, 3, 38-43. (in Chinese) [马克平, 刘灿然, 刘玉明 (1995) 
生物群落多样性的测度方法. II. $\beta$ 多样性的测度方法. 生 物多样性, 3, 38-43.]

Magurran AE (2011) Measuring Biological Diversity. Science Press, Beijing. (in Chinese) [张峰 (主译) (2011) 生物多样 性测度. 科学出版社, 北京.]

Mei J, Ran H, Yang TY, Xu QZ (2015) Species diversity of butterflies in Fanjing Mountain National Nature Reserve of Guizhou. Chinese Journal of Ecology, 34, 504-509. (in Chinese with English abstract) [梅杰, 再辉, 杨天友, 许勤 智 (2015) 贵州梵净山国家级自然保护区蝴蝶多样性. 生态学杂志, 34, 504-509.]

Nowicki P, Settele J, Henry PY, Woyciechowski M (2008) Butterfly monitoring methods: The ideal and the real world. Israel Journal of Ecology and Evolution, 54, 69-88.

Wahlberg N, Weingartner E, Nylin S (2003) Towards a better understanding of the higher systematics of Nymphalidae (Lepidoptera: Papilionoidea). Molecular Phylogenetics and Evolution, 2, 473-484.

Weng JQ, Lü WL, Hu SJ, Zheng JH, Li ZG (2017) Butterfly species diversity in Gutian Provincial Nature Reserve, Guangdong. Chinese Journal of Ecology, 36, 132-136. (in Chinese with English abstract) [翁锦洇, 吕文龙, 胡诗佳, 郑基焕, 李志刚 (2017) 广东古田自然保护区蝶类群落 多样性. 生态学杂志, 36, 132-136.]

Wu CS, Xu YF (2017) Butterflies of China. The Straits Publishing House, Fuzhou. (in Chinese) [武春生, 徐䏴峰 (2017) 中国蝴蝶图鉴. 海峡书局, 福州.]

Wu KJ, Gong PY, Sheng CF (2005) Estimation and expression of insect diversity parameters. Chinese Bulletin of Entomology, 42, 338-340. (in Chinese with English abstract) [吴坤君, 龚佩瑜, 盛承发 (2005) 昆虫多样性参 数的测定和表达. 昆虫知识, 42, 338-340.]

Yang DR (1998) Studies on the structure of the butterfly community and diversity in the fragmentary tropical rainforest of Xishuangbanna, China. Acta Entomologica Sinica, 41, 48-55. (in Chinese with English abstract) [杨大 荣 (1998) 西双版纳片断热带雨林蝴蝶群落结构与多样 性研究. 昆虫学报, 41, 48-55.]

Yuan CX, Liu CH, Xu SC, Zhao YL (2012) Faunal analysis of butterflies in Pingheliang Nature Reserve of Shaanxi Province. Journal of Anhui Agricultural Sciences, 40, 4478-4481. (in Chinese with English abstract) [苑彩霞, 刘 长海, 徐世才, 赵盈利 (2012) 陕西省平河梁自然保护区 蝶类资源调查及区系研究。安徽农业科学, 40, 4478-4481.]

Zhou X, Sun L, Pan WS, Lü Z, Ni YN (2001) The faunal study of the butterflies of the south slope of Qinling Mountains. Acta Scientiarum Naturalium Universitatis Pekinensis, 37, 454-469. (in Chinese with English abstract) [周欣, 孙路, 潘文石, 吕植, 倪一农 (2001) 秦岭南坡蝶类区系研究. 北京大学学报(自然科学版), 37, 454-469.]

Zuo ZT, Yuan XZ, Liu H, Li X (2008) Butterfly diversity in different types of habitat in Chongqing urban area. Chinese Journal of Ecology, 27, 946-950. (in Chinese with English abstract) [左自途, 袁兴中, 刘红, 黎璇 (2008) 重庆市主 城区不同生境类型的蝴蝶多样性. 生态学杂志, 27, 946-950.]

(责任编委: 白明 责任编辑: 间文杰)

\section{附录 Supplementary Material}

\section{附录1 秦岭国家植物园不同生境分布的蝴蝶种类}

Appendix 1 Butterfly species of the different habitats in Qinling National Botanical Garden

http://www.biodiversity-science.net/fileup/PDF/2020041-1.pdf 
房丽君, 张宇军, 邢小宇 (2020) 秦岭国家植物园蝴蝶群落结构与多样性。生物多样性, 28(8): 965-972. http://www.biodiversity-science.net/CN/10.17520/biods. 2020041

附录1 秦岭国家植物园不同生境分布的蝴蝶种类

Appendix 1 Butterfly species of the different habitats in Qinling National Botanical Garden

\begin{tabular}{|c|c|c|c|c|c|}
\hline $\begin{array}{l}\text { 种类 } \\
\text { Species }\end{array}$ & $\begin{array}{c}\text { 纯天然林 } \\
\text { Pure natural } \\
\text { forest } \\
\end{array}$ & $\begin{array}{c}\text { 天然林 } \\
\text { Natural forest }\end{array}$ & $\begin{array}{c}\text { 半人工林 } \\
\text { Semi-plantation }\end{array}$ & $\begin{array}{c}\text { 河岸带 } \\
\text { Riparian zone }\end{array}$ & $\begin{array}{c}\text { 农耕地 } \\
\text { Farmland }\end{array}$ \\
\hline \multicolumn{6}{|l|}{ 凤蝶科 Papilionidae } \\
\hline 金裳凤蝶 Troides aeacus & $\sqrt{ }$ & $\sqrt{ }$ & $\sqrt{ }$ & & \\
\hline 廂风蝶 Byasa alcinous & $\sqrt{ }$ & $\sqrt{ }$ & $\sqrt{ }$ & & \\
\hline 碧风蝶 Papilio bianor & $\sqrt{ }$ & $\sqrt{ }$ & $\sqrt{ }$ & & \\
\hline 蓝凤蝶 P. protenor & $\sqrt{ }$ & $\sqrt{ }$ & $\sqrt{ }$ & & \\
\hline 妹美凤蝶 P. macilentus & $\sqrt{ }$ & & & & \\
\hline 牛郎凤蝶 P. bootes & $\sqrt{ }$ & & & & \\
\hline 金凤蝶 P. machaon & & & & $\sqrt{ }$ & \\
\hline 柑橘凤蝶 P.xuthus & $\sqrt{ }$ & $\sqrt{ }$ & $\sqrt{ }$ & $\sqrt{ }$ & $\sqrt{ }$ \\
\hline 丝带凤蝶 Sericinus montelus & & $\sqrt{ }$ & & & \\
\hline 冰清绢蝶 Parnassius glacialis & $\sqrt{ }$ & $\sqrt{ }$ & $\sqrt{ }$ & & \\
\hline \multicolumn{6}{|l|}{ 粉蝶科 Pieridae } \\
\hline 斑缘豆粉蝶 Colias erate & $\sqrt{ }$ & $\sqrt{ }$ & $\sqrt{ }$ & $\sqrt{ }$ & $\sqrt{ }$ \\
\hline 橙黄豆粉蝶 C. fieldii & $\sqrt{ }$ & $\sqrt{ }$ & $\sqrt{ }$ & $\sqrt{ }$ & $\sqrt{ }$ \\
\hline 宽边黄粉蝶 Eurema hecabe & $\sqrt{ }$ & $\sqrt{ }$ & $\sqrt{ }$ & & \\
\hline 尖钩粉蝶 Gonepteryx mahaguru & & $\sqrt{ }$ & & & \\
\hline 绢粉蝶 Aporia crataegi & $\sqrt{ }$ & $\sqrt{ }$ & $\sqrt{ }$ & & \\
\hline 普通绢粉蝶 A.genestieri & $\sqrt{ }$ & $\sqrt{ }$ & $\sqrt{ }$ & & \\
\hline 灰姑娘绢粉蝶 A. intercostata & $\sqrt{ }$ & $\sqrt{ }$ & $\sqrt{ }$ & & \\
\hline 大翅绢粉蝶 A. largeteaui & $\sqrt{ }$ & $\sqrt{ }$ & $\sqrt{ }$ & & \\
\hline 菜粉蝶 Pieris rapae & $\sqrt{ }$ & $\sqrt{ }$ & $\sqrt{ }$ & $\sqrt{ }$ & $\sqrt{ }$ \\
\hline 东方菜粉蝶 P. canidia & $\sqrt{ }$ & $\sqrt{ }$ & $\sqrt{ }$ & $\sqrt{ }$ & $\sqrt{ }$ \\
\hline 暗脉菜粉蝶 P. napi & $\sqrt{ }$ & $\sqrt{ }$ & $\sqrt{ }$ & $\sqrt{ }$ & \\
\hline 黑纹粉蝶 P. melete & $\sqrt{ }$ & $\sqrt{ }$ & $\sqrt{ }$ & & \\
\hline 大展粉蝶 P. extensa & $\sqrt{ }$ & & & & \\
\hline 云粉蝶 Pontia daplidice & $\sqrt{ }$ & & $\sqrt{ }$ & $\sqrt{ }$ & $\sqrt{ }$ \\
\hline 红襟粉蝶 Anthocharis cardamines & $\sqrt{ }$ & $\sqrt{ }$ & & & \\
\hline 黄尖襟粉蝶 A. scolymus & $\sqrt{ }$ & $\sqrt{ }$ & $\sqrt{ }$ & & \\
\hline 突角小粉蝶 Leptidea amurensis & $\sqrt{ }$ & $\sqrt{ }$ & & & \\
\hline \multicolumn{6}{|l|}{ 蛱蝶科 Nymphalidae } \\
\hline 二尾蛱蝶 Polyura narcaea & $\sqrt{ }$ & $\sqrt{ }$ & $\sqrt{ }$ & & \\
\hline 柳紫闪蛱蝶 Apatura ilia & $\sqrt{ }$ & & $\sqrt{ }$ & & \\
\hline 曲带闪蛱蝶 A. laverna & $\sqrt{ }$ & & & & \\
\hline 迷蛱蝶 Mimathyma chevana & & $\sqrt{ }$ & & & \\
\hline 夜迷蛱蝶 M. nycteis & $\sqrt{ }$ & $\sqrt{ }$ & $\sqrt{ }$ & & \\
\hline 白斑迷蛱蝶 M. schrenckii & $\sqrt{ }$ & $\sqrt{ }$ & & & \\
\hline 猫蛱蝶 Timelaea maculata & & $\sqrt{ }$ & $\sqrt{ }$ & & \\
\hline 明窗蛱蝶 Dilipa fenestra & $\sqrt{ }$ & $\sqrt{ }$ & & & \\
\hline 累积蛱蝶 Lelecella limenitoides & $\sqrt{ }$ & $\sqrt{ }$ & & & \\
\hline 黄帅蛱蝶 Sephisa princeps & $\sqrt{ }$ & $\sqrt{ }$ & & & \\
\hline
\end{tabular}


房丽君, 张宇军, 邢小宇 (2020) 秦岭国家植物园蝴蝶群落结构与多样性. 生物多样性, 28(8): 965-972. http://www.biodiversity-science.net/CN/10.17520/biods. 2020041

\begin{tabular}{|c|c|c|c|c|c|}
\hline $\begin{array}{l}\text { 种类 } \\
\text { Species }\end{array}$ & $\begin{array}{c}\text { 纯天然林 } \\
\text { Pure natural } \\
\text { forest }\end{array}$ & $\begin{array}{c}\text { 天然林 } \\
\text { Natural forest }\end{array}$ & $\begin{array}{c}\text { 半人工林 } \\
\text { Semi-plantation }\end{array}$ & $\begin{array}{c}\text { 河岸带 } \\
\text { Riparian zone }\end{array}$ & $\begin{array}{c}\text { 农耕地 } \\
\text { Farmland }\end{array}$ \\
\hline 黑脉蛱蝶 Hestina assimilis & $\sqrt{ }$ & $\sqrt{ }$ & $\sqrt{ }$ & & \\
\hline 拟斑脉蛱蝶 $H$.persimilis & $\sqrt{ }$ & $\sqrt{ }$ & $\sqrt{ }$ & & \\
\hline 大紫蛱蝶 Sasakia charonda & $\sqrt{ }$ & $\sqrt{ }$ & $\sqrt{ }$ & & \\
\hline 绿豹蛱蝶 Argynnis paphia & $\sqrt{ }$ & $\sqrt{ }$ & $\sqrt{ }$ & & \\
\hline 斐豹蛱蝶 Argyreus hyperbius & $\sqrt{ }$ & $\sqrt{ }$ & $\sqrt{ }$ & $\sqrt{ }$ & \\
\hline 老豹蛱蝶 Argyronome laodice & $\sqrt{ }$ & $\sqrt{ }$ & & $\sqrt{ }$ & \\
\hline 红老豹蛱蝶 A. ruslana & $\sqrt{ }$ & & & & \\
\hline 云豹蛱蝶 Nephargynnis anadyomene & $\sqrt{ }$ & & $\sqrt{ }$ & & \\
\hline 灿福蛱蝶 Fabriciana adippe & & & $\sqrt{ }$ & & \\
\hline 扬眉线蛱蝶 Limenitis helmanni & $\sqrt{ }$ & $\sqrt{ }$ & $\sqrt{ }$ & & \\
\hline 戟眉线蛱蝶 L. homeyeri & & $\sqrt{ }$ & $\sqrt{ }$ & & \\
\hline 断眉线蛱蝶 L. doerriesi & $\sqrt{ }$ & $\sqrt{ }$ & $\sqrt{ }$ & & \\
\hline 残锷线蛱蝶 L. sulpitia & & & $\sqrt{ }$ & & \\
\hline 虬眉带蛱蝶 Athyma opalina & $\sqrt{ }$ & & & & \\
\hline 幸福带蛱蝶 A. fortuna & & $\sqrt{ }$ & & & \\
\hline 邚蛱蝶 Abrota ganga & $\sqrt{ }$ & $\sqrt{ }$ & $\sqrt{ }$ & & \\
\hline 锦瑟蛱蝶 Seokia pratti & $\sqrt{ }$ & $\sqrt{ }$ & & & \\
\hline 小环蛱蝶 Neptis sappho & $\sqrt{ }$ & $\sqrt{ }$ & $\sqrt{ }$ & & \\
\hline 啡环蛱蝶 N.philyra & $\sqrt{ }$ & $\sqrt{ }$ & $\sqrt{ }$ & & \\
\hline 羚环蛱蝶 N. antilope & & $\sqrt{ }$ & & & \\
\hline 矛环蛱蝶 N. armandia & $\sqrt{ }$ & $\sqrt{ }$ & & & \\
\hline 折环蛱蝶 N. beroe & $\sqrt{ }$ & $\sqrt{ }$ & & & \\
\hline 茂环蛱蝶 N. nemorosa & $\sqrt{ }$ & $\sqrt{ }$ & & & \\
\hline 蛛环蛱蝶 N. arachne & $\sqrt{ }$ & & & & \\
\hline 黄环蛱蝶 N. themis & $\sqrt{ }$ & $\sqrt{ }$ & $\sqrt{ }$ & & \\
\hline 海环蛱蝶 N. thetis & & $\sqrt{ }$ & & & \\
\hline 朝鲜环蛱蝶 N. philyroides & $\sqrt{ }$ & $\sqrt{ }$ & $\sqrt{ }$ & & \\
\hline 链环蛱蝶 N. pryeri & $\sqrt{ }$ & $\sqrt{ }$ & $\sqrt{ }$ & & \\
\hline 重环蛱蝶 N. alwina & $\sqrt{ }$ & $\sqrt{ }$ & $\sqrt{ }$ & & \\
\hline 提环蛱蝶 $N$. thisbe & $\sqrt{ }$ & $\sqrt{ }$ & $\sqrt{ }$ & & \\
\hline 黑条伞蛱蝶 Aldania raddei & $\sqrt{ }$ & $\sqrt{ }$ & & & \\
\hline 大红蛱蝶 Vanessa indica & $\sqrt{ }$ & $\sqrt{ }$ & & & \\
\hline 小红蛱蝶 V. cardui & $\sqrt{ }$ & & $\sqrt{ }$ & $\sqrt{ }$ & \\
\hline 琉璃蛱蝶 Kaniska canace & $\sqrt{ }$ & $\sqrt{ }$ & $\sqrt{ }$ & & \\
\hline 黄钩蛱蝶 Polygonia c-aureum & $\sqrt{ }$ & $\sqrt{ }$ & $\sqrt{ }$ & $\sqrt{ }$ & $\sqrt{ }$ \\
\hline 白钩蛱蝶 P. c-album & & $\sqrt{ }$ & $\sqrt{ }$ & & \\
\hline 曲纹蜘蛱蝶 Araschnia doris & $\sqrt{ }$ & & & & \\
\hline 断纹蜘蛱蝶 A. dohertyi & $\sqrt{ }$ & & & & \\
\hline 布网蜘蛱蝶 A. burejana & $\sqrt{ }$ & $\sqrt{ }$ & & & \\
\hline 帝网蛱蝶 Melitaea diamina & $\sqrt{ }$ & $\sqrt{ }$ & & & \\
\hline 大网蛱蝶 $M$. scotosia & $\sqrt{ }$ & $\sqrt{ }$ & & & \\
\hline 大卫绢蛱蝶 Calinaga davidis & $\sqrt{ }$ & $\sqrt{ }$ & $\sqrt{ }$ & & \\
\hline
\end{tabular}


房丽君, 张宇军, 邢小宇 (2020) 秦岭国家植物园蝴蝶群落结构与多样性. 生物多样性, 28(8): 965-972. http://www.biodiversity-science.net/CN/10.17520/biods. 2020041

\begin{tabular}{|c|c|c|c|c|c|}
\hline $\begin{array}{l}\text { 种类 } \\
\text { Species }\end{array}$ & $\begin{array}{c}\text { 纯天然林 } \\
\text { Pure natural } \\
\text { forest }\end{array}$ & $\begin{array}{c}\text { 天然林 } \\
\text { Natural forest }\end{array}$ & $\begin{array}{c}\text { 半人工林 } \\
\text { Semi-plantation }\end{array}$ & $\begin{array}{c}\text { 河岸带 } \\
\text { Riparian zone }\end{array}$ & $\begin{array}{c}\text { 农耕地 } \\
\text { Farmland }\end{array}$ \\
\hline 黑绢蛱蝶 C. lhatso & $\sqrt{ }$ & $\sqrt{ }$ & & & \\
\hline 朴喙蝶 Libythea celtis & & $\sqrt{ }$ & & & \\
\hline 黛眼蝶 Lethe dura & $\sqrt{ }$ & & & & \\
\hline 棕褐黛眼蝶 L. christophi & & & $\sqrt{ }$ & & \\
\hline 蒙链荫眼蝶 Neope muirheadii & $\sqrt{ }$ & & & & \\
\hline 稻眉眼蝶 Mycalesis gotama & & $\sqrt{ }$ & & & \\
\hline 拟稻眉眼蝶 $M$. francisca & $\sqrt{ }$ & $\sqrt{ }$ & $\sqrt{ }$ & & \\
\hline 白眼蝶 Melanargia halimede & $\sqrt{ }$ & & & & \\
\hline 蛇眼蝶 Minois dryas & & $\sqrt{ }$ & & & \\
\hline 古眼蝶 Palaeonympha opalina & & $\sqrt{ }$ & & & \\
\hline 㪬眼蝶 Ypthima baldus & $\sqrt{ }$ & $\sqrt{ }$ & $\sqrt{ }$ & & \\
\hline 中华唯眼蝶 Y. chinensis & $\sqrt{ }$ & & & & \\
\hline 东亚翬眼蝶 Y. motschulskyi & $\sqrt{ }$ & $\sqrt{ }$ & $\sqrt{ }$ & & \\
\hline 灰蝶科 Lycaenidae & & & & & \\
\hline 蚜灰蝶 Taraka hamada & $\sqrt{ }$ & & & & \\
\hline 陕灰蝶 Shaanxiana takashimai & & & $\sqrt{ }$ & & \\
\hline 华灰蝶 Wagimo sulgeri & $\sqrt{ }$ & & & & \\
\hline 霓纱燕灰蝶 Rapala nissa & & & $\sqrt{ }$ & & \\
\hline 蓝燕灰蝶 R. caerulea & $\sqrt{ }$ & $\sqrt{ }$ & $\sqrt{ }$ & & \\
\hline 红斑酒灰蝶 Satyrium rubicundulum & $\sqrt{ }$ & & & & \\
\hline 优秀酒灰蝶 S. eximia & $\sqrt{ }$ & & & & \\
\hline 刺疬洒灰蝶 S. spini & & $\sqrt{ }$ & & & \\
\hline 红灰蝶 Lycaena phlaeas & $\sqrt{ }$ & $\sqrt{ }$ & & $\sqrt{ }$ & $\sqrt{ }$ \\
\hline 莎菲彩灰蝶 Heliophorus saphir & $\sqrt{ }$ & & & & \\
\hline 黑灰蝶 Niphanda fusca & $\sqrt{ }$ & $\sqrt{ }$ & & & \\
\hline 锯灰蝶 Orthomiella pontis & $\sqrt{ }$ & $\sqrt{ }$ & $\sqrt{ }$ & $\sqrt{ }$ & \\
\hline 中华锯灰蝶 $O$. sinensis & $\sqrt{ }$ & $\sqrt{ }$ & & & \\
\hline 酢浆灰蝶 Pseudozizeeria maha & $\sqrt{ }$ & $\sqrt{ }$ & $\sqrt{ }$ & $\sqrt{ }$ & $\sqrt{ }$ \\
\hline 蓝灰蝶 Everes argiades & $\sqrt{ }$ & $\sqrt{ }$ & $\sqrt{ }$ & $\sqrt{ }$ & $\sqrt{ }$ \\
\hline 玄灰蝶 Tongeia fischeri & $\sqrt{ }$ & $\sqrt{ }$ & $\sqrt{ }$ & & \\
\hline 点玄灰蝶 T. filicaudis & $\sqrt{ }$ & $\sqrt{ }$ & $\sqrt{ }$ & $\sqrt{ }$ & $\sqrt{ }$ \\
\hline 雾驳灰蝶 Bothrinia nebulosa & $\sqrt{ }$ & & & & \\
\hline 璃灰蝶 Celastrina argiola & $\sqrt{ }$ & $\sqrt{ }$ & & & \\
\hline 大紫璃灰蝶 C. oreas & $\sqrt{ }$ & $\sqrt{ }$ & $\sqrt{ }$ & $\sqrt{ }$ & $\sqrt{ }$ \\
\hline 靛灰蝶 Caerulea coeligena & $\sqrt{ }$ & $\sqrt{ }$ & $\sqrt{ }$ & & \\
\hline 珞灰蝶 Scolitantides orion & $\sqrt{ }$ & $\sqrt{ }$ & & & \\
\hline 豆灰蝶 Plebejus argus & & & & $\sqrt{ }$ & \\
\hline 红珠灰蝶 Lycaeides argyrognomon & & & $\sqrt{ }$ & $\sqrt{ }$ & \\
\hline 多眼灰蝶 Polyornmatus erotides & & & & $\sqrt{ }$ & \\
\hline \multicolumn{6}{|l|}{ 弄蝶科 Hesperiidae } \\
\hline 绿弄蝶 Choaspes benjaminii & $\sqrt{ }$ & & & & \\
\hline 双带弄蝶 Lobocla bifasciata & $\sqrt{ }$ & $\sqrt{ }$ & $\sqrt{ }$ & & \\
\hline
\end{tabular}


房丽君, 张宇军, 邢小宇 (2020) 秦岭国家植物园蝴蝶群落结构与多样性. 生物多样性, 28(8): 965-972. http://www.biodiversity-science.net/CN/10.17520/biods. 2020041

\begin{tabular}{|c|c|c|c|c|c|}
\hline $\begin{array}{l}\text { 种类 } \\
\text { Species }\end{array}$ & $\begin{array}{c}\text { 纯天然林 } \\
\text { Pure natural } \\
\text { forest }\end{array}$ & $\begin{array}{c}\text { 天然林 } \\
\text { Natural forest }\end{array}$ & $\begin{array}{c}\text { 半人工林 } \\
\text { Semi-plantation }\end{array}$ & $\begin{array}{c}\text { 河岸带 } \\
\text { Riparian zone }\end{array}$ & $\begin{array}{c}\text { 农耕地 } \\
\text { Farmland }\end{array}$ \\
\hline 深山珠弄蝶 Erynnis montanus & & $\sqrt{ }$ & & & \\
\hline 白弄蝶 Abraximorpha davidii & $\sqrt{ }$ & $\sqrt{ }$ & $\sqrt{ }$ & & \\
\hline 黑弄蝶 Daimio tethys & $\sqrt{ }$ & $\sqrt{ }$ & $\sqrt{ }$ & & \\
\hline 花窗弄蝶 Coladenia hoenei & $\sqrt{ }$ & $\sqrt{ }$ & $\sqrt{ }$ & & \\
\hline 梳翅弄蝶 Ctenoptilum vasava & $\sqrt{ }$ & $\sqrt{ }$ & & & \\
\hline 直纹稻弄蝶 Parnara guttata & $\sqrt{ }$ & & $\sqrt{ }$ & & \\
\hline 南亚谷弄蝶 Pelopidas agna & $\sqrt{ }$ & $\sqrt{ }$ & & & \\
\hline 中华谷弄蝶 P. sinensis & $\sqrt{ }$ & & & & $\sqrt{ }$ \\
\hline 隐纹谷弄蝶 P. mathias & $\sqrt{ }$ & $\sqrt{ }$ & & & \\
\hline 小赫弄蝶 Ochlodes venata & $\sqrt{ }$ & $\sqrt{ }$ & $\sqrt{ }$ & & \\
\hline 透斑赫弄蝶 $O$. linga & $\sqrt{ }$ & $\sqrt{ }$ & $\sqrt{ }$ & & \\
\hline 白斑赫弄蝶 O. subhyalina & $\sqrt{ }$ & $\sqrt{ }$ & & & \\
\hline 豹弄蝶 Thymelicus leoninus & $\sqrt{ }$ & $\sqrt{ }$ & & & \\
\hline 黑豹弄蝶 T. sylvaticus & $\sqrt{ }$ & & & & \\
\hline 钩形黄斑弄蝶 Ampittia virgata & $\sqrt{ }$ & $\sqrt{ }$ & & & \\
\hline
\end{tabular}

